\title{
Ventricular Shunting Paradigm in Surgical Management of Arrested Hydrocephalus in Children with Distorted Mental Status
}

\author{
MAHMOUD SAAD, M.D.; MOHAMED RAAFAT, M.Sc.; AHMED ZAHER, M.D. and HATEM BADR, M.D. \\ The Department of Neurosurgery, Faculty of Medicine, Mansoura University, Egypt
}

\begin{abstract}
Background: Wide range of psychomotor development abnormalities can occur in compensated hydrocephalus, ranging from minor cognitive changes up to mental retardation; this may be attributed to the difficulty in differentiation between compensated hydrocephalus and slowly progressive hydrocephalus.
\end{abstract}

Aim of Study: To establish whether CSF shunting procedures can improve the cognitive development in children with arrested hydrocephalus and apparent clinically normal.

Patients and Methods: This study is a prospective randomized controlled trial included 20 consecutive children with arrested hydrocephalus in preschool age with no other cause of mental retardation. All the patients had deviated IQ (intelligence quotient) below than average) and they were subdivided into 2 groups: Group I control group; 10 patients had been followed-up clinically and group II study group; 10 patients had been surgically managed through ventriculoperitoneal shunting. Anterior fontanelle, orbitofrontal circumference and IQ are assessed initially and 6 months later and compared in both groups.

Results: Ventricular shunt improved papilledema (5 out of 6 became normal fundi), improved cognitive function ( 5 out of 8 mild MR became average 90-110 IQ test). Ventricular shunt did not improve the ventricular size in all patients in both groups who still having papilledema.

Conclusions: Young children with arrested HCP without any signs of increased ICP and average IQ should be followed carefully to detect any cognitive delay or decompansation. Ventricular shunting is helpful to improve psychomotor development in patients with cognitive delay.

Key Words: Arrested hydrocephalus - Cognitive impairment - Shunting - Anterior fontanel - Orbitofrontal circumference.

\section{Introduction}

ARRESTED hydrocephalus is chronic form of exceptionally enlarged ventricles with no typical signs of raised intracranial tension [1]. There are

Correspondence to: Dr. Mahmoud Saad, The Department of Neurosurgery, Faculty of Medicine, Mansoura University, Egypt confusing terms used to describe this condition, such as Syndrome of Hydrocephalus in Young and Middle Aged adults (SHYMA), Late-onset Idiopathic Aqueductal Stenosis, (LIAS), Longstanding Overt Ventriculomegaly in Adults (LOVA), and late-onset aqueductal stenosis (AS) whenever others consider LOVA is a special form of LIAS [1] .

In arrested hydrocephalus, ventricular dilatation is due to remote obstructive episode, while lack of increased tension evidenced by absent transependymal permeation due to development of equilibrium in CSF pathway [2]

Many theories described the pathogenesis of arrested hydrocephalus; it occur when CSF production equals absorption, intra-ventricular pressure has returned to normal, and there is no neurological dysfunction or abnormal increase in head circumference, the cause of this compensatory mechanism remains not totally clarified [3]. One theory of this compensatory mechanism, that it is due to development of transependymal intraparenchymal CSF resorption pathway. Another theory, the compensation may occur due to spontaneous ventriculostomy, which is rupture of the walls of the ventricles resulting in direct communication between the ventricular system and subarachnoid space leading to internal drainage of CSF and reduce intracranial tension [4].

\footnotetext{
Abbreviations:

SHYMA : Syndrome of Hydrocephalus in Young and Middle Aged adults.

LIAS : Late-onset Idiopathic Aqueductal Stenosis.

LOVA : Longstanding Overt Ventriculomegaly in Adults.

AS : Aqueductal Stenosis.

CSF : Cerebrospinal Fluid.

ICP : Intracranial Pressure.

$p \quad: p$-value for comparing between the groups.

MC : Monte Carlo

FE : Fisher Exact.
} 
Wide range of psychomotor development abnormalities can occur in compensated hydrocephalus, ranging from minor cognitive changes up to mental retardation; this may be attributed to the difficulty in differentiation between compensated hydrocephalus and slowly progressive hydrocephalus, with its risk of ongoing parenchymal damage [5].

The treatment of arrested hydrocephalus is a matter of debate about the optimum treatment. Most institutes prefer expectant management of arrested hydrocephalus [6]. On the other hand, the use of shunting procedure for management of arrested hydrocephalus is practiced by some institutes; they claim that the use of shunting procedures prevents psychomotor development abnormalities, which occur due to decompansation with progression to active form or slowly progressive hydrocephalus [7].

\section{Patients and Methods}

This study is a prospective randomized controlled trial (randomization via sealed envelope and family counselling) included 20 consecutive children with arrested hydrocephalus in preschool age with no other cause of mental retardation. Active hydrocephalus and elder children were excluded from the study.

The study performed in Pediatric Unit, Neurosurgery Department, Mansoura University Hospitals within the period from February 2017 to October 2018. All patients who were enrolled in the study recorded to have deviated IQ (intelligenc equotient) from normal (below than average) and then they were subdivided into 2 groups: Group I 'control group' 10 patients had been followed-up clinically and group II 'study group' 10 patients had been surgically managed through ventriculoperitoneal shunting.

All Participants were subjected to standard clinical evaluation; all patients' medical record was obtained. We evaluated the ventricular size in both groups through neuroimaging studies: Computed tomography (CT brain or MRI). From the CT several measurements and ratioswere obtained and considered Fig. (1) mainly Evans index.

All children were initially underwent neuropsychological examination and all were re-assessed 6 months later. The tests were administered in the same order and by the same examiner. Villand adaptive behavior test was used to evaluate IQ for children below 9 months of age while Stanford Binnet was performed for children for older children.

Treatment plan for children in the study group was surgical intervention in the form of ventriculoperitoneal shunt implantation. Ventricular size and ICP recording were used to decide the most appropriate valve. While, the control group were followed-up conservatively. Initial follow-up of the children was done via clinical and radiological assessment of all patients and then after six months interval through neuropsychological and radiological assessment. Parents of control group children were advised to seek our medical advice urgently as soon as the child develops any symptoms or signs of raised ICP.

The Statistical Package for the Social Sciences (Version 20) was used for data analysis. For group comparisons we used Mann-Whitney U procedures. Statistical significance was established at $p<0.01 \%$.

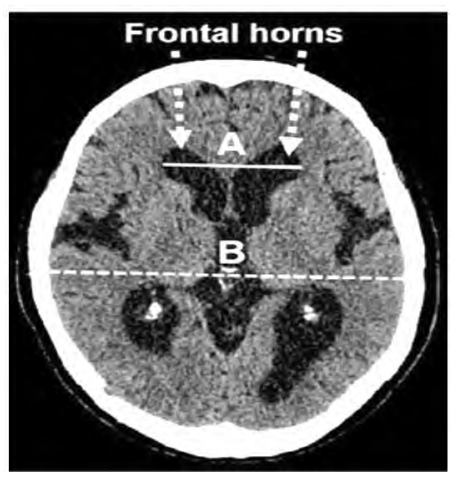

Evans index $=\mathrm{A} / \mathrm{B}$

Fig. (1): The Evans ratio is defined as the maximum ventricular width (A) divided by the largest biparietal distance between the inner tables of the skull (B). An Evans ratio of at least 0.3 may be consistent with a diagnosis of hydrocephalus.

\section{Results}

The study included 20 patients age up to 24 month, 9 males and 11 females with no statistical differences between the two studied groups and in this study. We excluded any child with CNS anomaly which could be a cause of mental retardation and three cases had other unrelated anomaly two had VSD and one child had PDA.

In our study the, pre management Orbitofrontal Circumference (OFC) was found to be normal or within 2 SD in 8 children, while only was more than 2 SD in 2 cases. In group II, $50 \%$ of cases had OFC more than 2 SD and there was a statistical significance between the two studied groups ( MCP $=0.437$ ). 
Table (1): Clinical hydrocephalic parameters compared both initially at six month follow-up between the two groups.

\begin{tabular}{|c|c|c|c|c|c|c|}
\hline & \multicolumn{3}{|c|}{ OFC } & \multicolumn{3}{|c|}{ Ant Font } \\
\hline & & Initial & $6 \mathrm{~m}$ follow-up & & Initial & $6 \mathrm{~m}$ follow-up \\
\hline Group I Control & $\begin{array}{l}\text { Normal } \\
\text { Within } 2 \mathrm{SD} \\
>2 \mathrm{SD}\end{array}$ & $\begin{array}{l}4(40 \%) \\
4(40 \%) \\
2(20 \%)\end{array}$ & $\begin{array}{l}4(40 \%) \\
4(40 \%) \\
2(20 \%)\end{array}$ & $\begin{array}{l}\text { Normal } \\
\text { Bulge } \\
\text { Tense }\end{array}$ & $\begin{array}{l}6(60 \%) \\
4(40 \%) \\
0\end{array}$ & $\begin{array}{l}6(60 \%) \\
4(40 \%) \\
0\end{array}$ \\
\hline Group II Study & $\begin{array}{l}\text { Normal } \\
\text { Within 2SD } \\
>2 \text { SD }\end{array}$ & $\begin{array}{l}2(20 \%) \\
3(30 \%) \\
5(50 \%)\end{array}$ & $\begin{array}{l}2(20 \%) \\
5(50 \%) \\
3(30 \%)\end{array}$ & $\begin{array}{l}\text { Normal } \\
\text { Bulge } \\
\text { Tense }\end{array}$ & $\begin{array}{l}3(30 \%) \\
7(70 \%) \\
0\end{array}$ & $\begin{array}{l}6(60 \%) \\
4(40 \%) \\
0\end{array}$ \\
\hline
\end{tabular}

In group II $60 \%$ of cases had normal AF, while in group I 70\% of patients had bulge AF with statistical difference between two groups $\left(\mathrm{MC}_{p}\right.$ 0.370 ) and none of patients in this study has tense AF (Table 1). Proper fundus examination was performed to all cases by ophthalmologist and $80 \%$ of group I patients had normal fundus while in group II $80 \%$ of patient had grade I papilledema with statistical difference between the two groups $\left(\mathrm{MC}_{p}, 0.170\right)$. None of our patients had higher grades of papilledema.

All our cases had ventriculomegaly on MRI and CT brain and $75 \%$ of hydrocephalus was of obstructive variety, while communicating type represented $25 \%$ of cases. Ventricular permeation on MRI was noticed in $80 \%$ of group II patients, while only recorded in $40 \%$ in group I with statistical difference between the two groups ( FE $p=1.000$ ) (Table 2). None of patients in both groups had any other pathology on MRI or CT brain as tumors, infection, and anomalies.

Table (2): Radiological hydrocephalic metrics and sings between the two groups initially and at six month follow-up.

\begin{tabular}{|c|c|c|c|}
\hline & \multicolumn{3}{|c|}{ Radiological assessment } \\
\hline & & Initial & $\begin{array}{c}6 \mathrm{~m} \\
\text { follow-up }\end{array}$ \\
\hline \multirow{6}{*}{$\begin{array}{l}\text { Group I } \\
\text { Control }\end{array}$} & • Ventriculomegaly (CT) & 10 & 10 \\
\hline & • Type of hydrocephalus (CT) & & \\
\hline & - Obstructing & 7 & 7 \\
\hline & - Communicating & 3 & 3 \\
\hline & - Ventricular permeation (MRI) & 4 & 4 \\
\hline & - Evans ratio $(\mathrm{CT})$ & $<0.3$ & $<0.3$ \\
\hline \multirow{6}{*}{$\begin{array}{l}\text { Group II } \\
\text { Study }\end{array}$} & • Ventriculomegaly (CT) & 10 & 10 \\
\hline & - Type of hydrocephalus (CT) & & \\
\hline & - Obstructing & 8 & 8 \\
\hline & - Communicating & 2 & 2 \\
\hline & - Ventricular permeation (MRI) & 8 & 4 \\
\hline & - Evans ratio $(\mathrm{CT})$ & $<0.3$ & $<0.3$ \\
\hline
\end{tabular}

During recording the cognitive status of patients of this study, before clinical trial, we noticed that $20 \%$ of group I patients had mild MR while $80 \%$ percent of group II patients had a mild MR with statistical difference between the two groups $\left(\mathrm{MC}_{p}\right.$ 0.095) (Table 3).

Table (3): Initial psychological assessent and at six month follow-up for both groups.

\begin{tabular}{llcc}
\hline & \multicolumn{3}{c}{ IQ } \\
\cline { 2 - 4 } & Intelligence scale & Initial & 6m follow-up \\
\hline Group I & Excellent (>120) & 0 & 0 \\
Control & Average (90-110) & 0 & 0 \\
& Mild MR (50-90) & 9 & 9 \\
& Moderate MR (30-50) & 1 & 1 \\
& Severe MR (25-30) & 0 & 0 \\
Group II & Excellent (>120) & 0 & 0 \\
Study & Average (90-110) & 0 & 5 \\
& Mild MR (50-90) & 8 & 3 \\
& Moderate MR (30-50) & 2 & 2 \\
& Severe MR (25-30) & 0 & 0 \\
\hline
\end{tabular}

At six months interval of beginning the study; as regard OFC; in-group II 70\% of children became either normal or within 2SD with no statistical significant between 2 groups. With treatment, $60 \%$ of group II children had normal AF while $40 \%$ still had bulging anterior fontanel. No statistical difference between the two groups after treatment (Table 1).

In group II, 6 months follow-up showed improvement of papilledema, but one patient only still has grade I papilledema and there was no statistical difference between 2 groups (Table 4). Ventricular shunt did not improve the ventricular size and all patients in 2 groups who still having papilledema.

Table (4): Ophthalmological assessment (fundus examination) of the two studied groups.

\begin{tabular}{llcc}
\hline & \multicolumn{3}{c}{ Fundus examination } \\
\cline { 2 - 4 } & & Initial & 6m follow-up \\
\hline \multirow{2}{*}{ Group I } & Normal fundus & 8 & 8 \\
Control & Papilledema G I & 2 & 2 \\
& Papilledema G II-IV & 0 & 0 \\
Group II & Normal fundus & 4 & 9 \\
Study & Papilledema G I & 6 & 1 \\
& Papilledema G II-IV & 0 & 0 \\
\hline
\end{tabular}


In group II patients, initial neuropsychological assessment 8 patients had mild MR (50-90 IQ test) and 2 patients moderate MR (30-50 IQ test) and at 6 months interval follow-up, the 2 patients did not improve while 5 of 8 mild MR became average (90-110 IQ test) and the other 3 did not improve. While no statistical significance was recorded between the two groups (Table 3 ).

\section{Illustrated cases:}

Case I:

Male child aged 18 months with no signs of active $\mathrm{HCP}$, bulging $\mathrm{AF}$, and $\mathrm{HC}$ within $2 \mathrm{SD}$ and had no papilledema, his IQ test was below average initially Fig. (2A) and the child was observed for 6 months Fig. (2B) and his IQ test was the same.
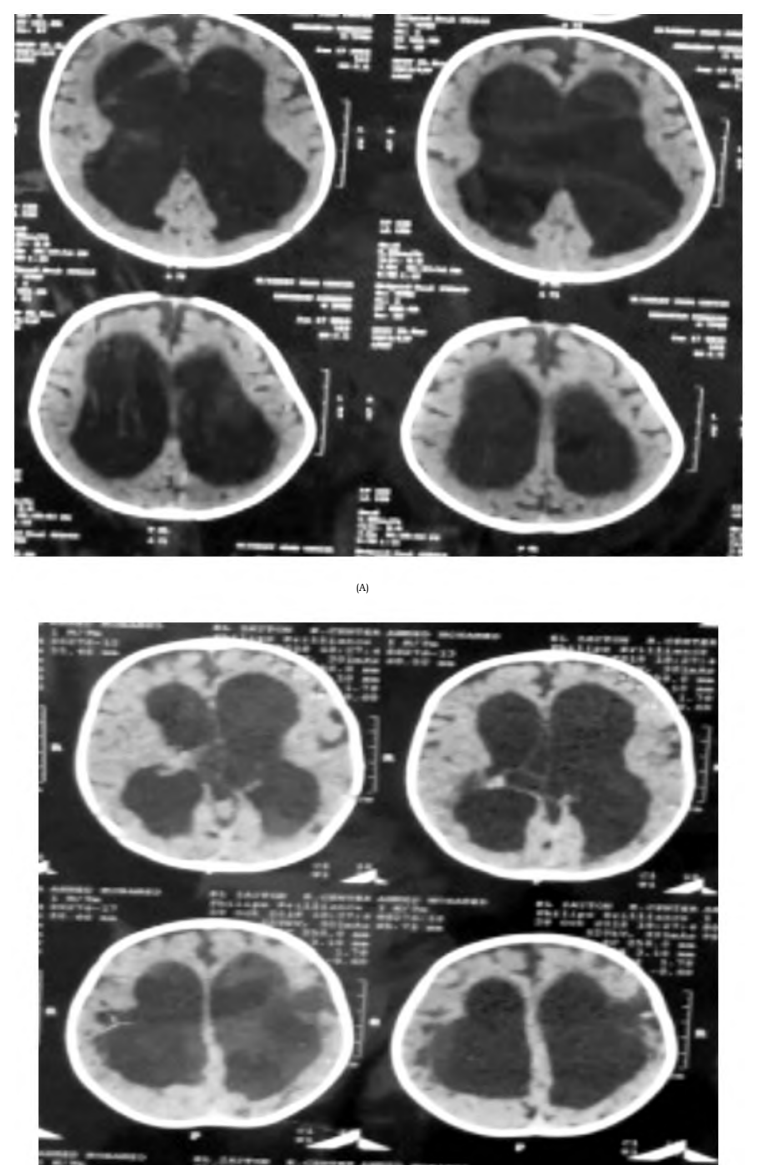

Fig. (2): Initial CT brain (2A) and follow-up CT after 6 months in a child (2B) with arrested hydrocephalus in the control group.

Case II:

Female child aged 23 months with no signs of active $\mathrm{HCP}$, bulging $\mathrm{AF}$, and $\mathrm{HC}$ within $2 \mathrm{SD}$ and had no papilledema, his IQ test was below average initially Fig. (3A) and the child was shunted Fig. (3B) with improving IQ test to average (Sanford Biennet Test).
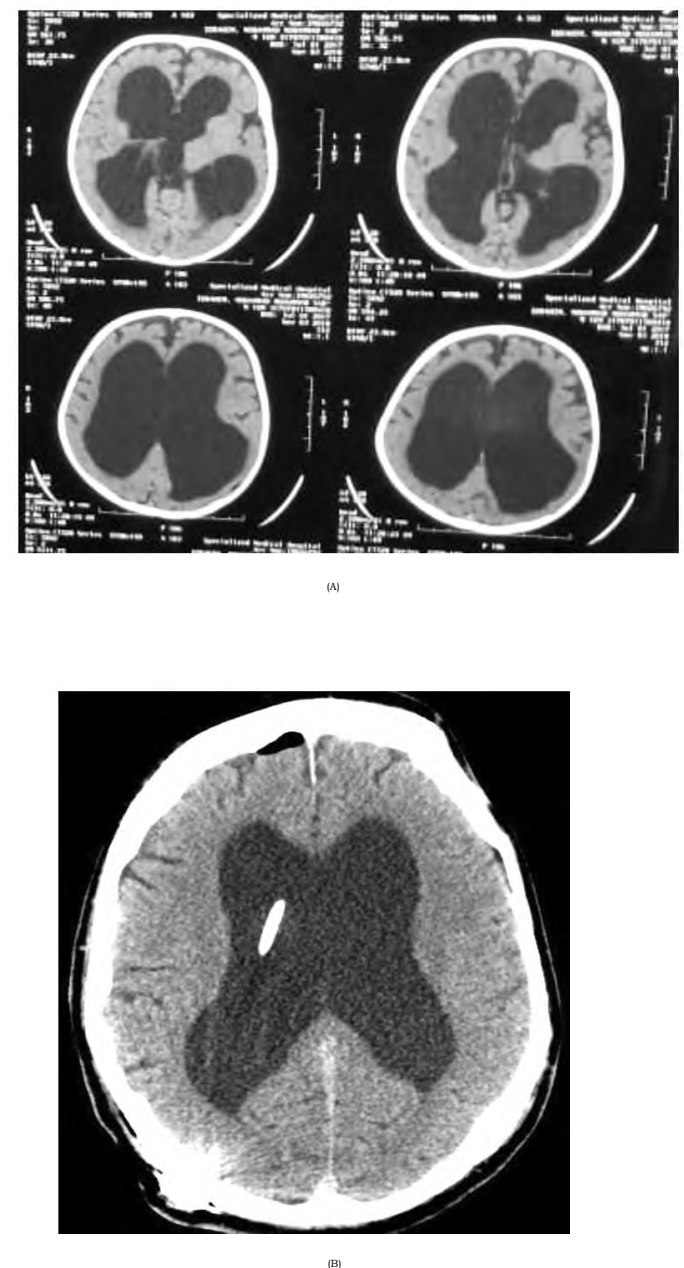

Fig. (3): Initial CT brain (3A) and follow-up CT after 6 months of shunt implantation (3B) in a child with arrested hydrocephalus in the study group.

\section{Discussion}

Management of arrested HCP shows a great debate, while most institutes practice a non-surgical treatment of such a condition, a little advice the introduction of some sort of surgical intervention (mostly VPS) as a primary management of assumed arrested (HCP). Advocates of non-surgical treatment claims that the introduction of a VPS in a child without any solid evidence of ICT-HTN has many side effects as exposure of a child to such a complicated unnecessary surgery. On the other hand, few authors claim that it is not a purely compensated HCP, there is actually ongoing brain damage, and they introduce the term (assumed) to describe the condition, so using a VPS is very useful in the prevention of such brain damage by prevention of unnoticed or more accurately episodes of raised ICT [11]

Lacking of studies remains a challenge to advocate any of previously described modalities as a primary effective method for treating such a 
condition. In this study, we tried to prove or disprove the efficacy of VPS as a primary line of management of arrested HCP; we introduce the IQ assessment as a parameter in addition to the other conventional clinical parameters. In addition, we selected the (ventriculomegaly without any clinical signs of IC-HTN) as a definition of arrested $\mathrm{HCP}$, among many introduces detentions described in the literature [12].

Our recent trial included 20 consecutive patients with arrested hydrocephalus in preschool age with no other cause of mental retardation. Ventriculomegaly recorded despite the absence of overt clinical signs of increased ICP. It is important to stress that it is often so difficult to distinguish between compensated hydrocephalus, without risk of brain damage, and slowly progressive hydrocephalus, with its risk of ongoing parenchymal damage [8]

The demographic data of this series indicated that most of cases were in age group 7-12 months of age, which differs from, Whittle, et al. [8] and Zieli'nska, et al. [13] who select older age group for both studies to facilitate the neuropsychological assessment. In our trial, we had 11 females and 9 males; Parents of our studied cases were relatives in only 7 cases with no implication on the siblings and no statistical differences between the two groups. $25 \%$ of our study cases were premature, all of them admitted to incubator and they had no other risk factor for developing hydrocephalus. 3 cases had associated anomalies, which were cardiovascular and had no implication on the IQ development. We exclude any case with other CNS abnormality which because it can affect both cognitive and motor development (obstructive $\mathrm{HCP}$ due to tumor).

All our cases had ventriculomegaly on MRI and CT brain pre-operatively as well as post operatively, $75 \%$ of hydrocephalus was of obstructive variety, while communicating type represented $25 \%$ of cases. No statistical difference between the two groups regarding the ventricular size ( $p=$ 1.000), also after surgery, OFC remain the same in both groups with no statistical significance between them $(p=1.000)$. This differs from Hammock, et al. [6], Di Rocco, et al. [9], studies who recorded reduction of ventricular size after treatment, this attributed to longer follow-up period in both studies.

All the cases enrolled inour study had below average IQ test (inclusion criteria); most of them were mild MR ( 9 cases in each group) with no statistical significance $(p=0.595)$ (Table 3$)$. After
6 months follow-up, IQ improved in group II cases ( 5 cases out of 8 had average IQ test and one out of two cases which had moderate MR became mild MR) with statistical significance between the two groups $(p=0.395)$. The pervious data similar to Hammock et al. [6] series, in which improvement in IQ was recorded after treatment, despite the difference in age, sample size and also superimposed menigeomyelocele between the both studies. Fortunately, none of group I cases deteriorated as regard the IQ test, but also there was no improvement after comparing initial IQ to IQ after 6 months of conservative treatment ( $p=0.595)$.

\section{Limitation of study:}

The main limitation of our study was the relatively short follow-up period (6 months). Future strategy for longer follow-up period, larger cohort trial is planned aiming at further assessment of the effect on VP shunt on OFC, ventricular size together with detection of shunt complication, which not recorded in our study. And also for accurate detection of any developmental delay or clinical signs of increased ICP which could be occur at any time due to any obstructive episode or decomposition.

\section{Conclusion:}

The dilemma of management of arrested hydrocephalus is a matter of debate about the optimum treatment. Most institutes prefer expectant management of arrested hydrocephalus, with stressing on education of families to seek medical attention if they develop symptoms of intracranial hypertension [13].

Proper evaluation of any child with assumed arrested HCP clinical, radiological and neuropsychological assessment with recommendation of expectant treatment of those who have accepted developmental score, on the other hand, early CSF shunting is indicated when any developmental delay recorded.

\section{Compliance with ethical standards:}

Funding: No funding was received for this research.

Conflict of interest: All authors certify that they have no affiliations with or involvement in any organization or entity with any financial interest, or non-financial interestin the subject matter or material was discussed in this manuscript.

Ethical approval: The study design and procedure performed in the study were in accordance with the ethical standards of the institutional research board at Mansoura College of Medicineand 
with the 1964 Helsinki declaration and its later amendments.

Informed consent: Informed consent was obtained from all parents of children participated in the study after detailed counselling.

\section{References}

1- DENNIS M., FITZ C.R., NETLEY C.T., et al.: The intelligence of hydrocephalic children. Arch. Neurol., 38: 607$15,2000$.

2- HURNI Y., PORETTI A., SCHNEIDER J., et al.: Arrested Hydrocephalus in Childhood: Case Series and Review of the Literature. Neuropediatrics, 49 (5): 302-9, 2018.

3- HANLO P.W., GOOSKENS R.J., VAN SCHOONEVELD M., et al.: The effect of intracranial pressure on myelination and the relationship with neurodevelopment in infantile hydrocephalus. Dev. Med. Child Neurol., 39: 286-91, 2009.

4- THOMPSON M.G., EISENBERG H.M. and LEVIN H.S. Hydrocephalic infants: Developmental assessment and computed tomography. Childs Brain, 9: 400-10, 2005.

5- LIECHTY E.A., GILMOR R.L., BRYSON C.Q., et al.: Outcome of high-risk neonates with ventriculomegaly. Dev. Med. Child Neurol., 25: 162-8, 2000.

6- HAMMOCK M.K., MILHORAT T.H. and BARON I.S.: Normal pressure hydrocephalus in patients with myelomeningocele. Dev. Med. Child Neurol., Suppl., 55-68, 1976.
7- DI ROCCO C., CALDARELLI M., MAIRA G., et al.: The study of cerebrospinal fluid dynamics in apparently "arrested" hydrocephalus in children. Childs Brain, 3: 359-74, 1977.

8- WHITTLE I.R., JOHNSTON I.H. and BESSER M.: Intracranial pressure changes in arrested hydrocephalus. J. Neurosurg., 62: 77-82, 2015.

9- TORKELSON R.D., LEIBROCK L.G., GUSTAVSON J.L., et al.: Neurological and neuropsychological effects of cerebral spinal fluid shunting in children with assumed arrested (normal pressure) hydrocephalus. J. Neurol. Neurosurg Psychiatry, 48: 799-806, 1985.

10- KIRK PATRICK M., ENGLEMAN H. and MINNS R.A.: Symptoms and signs of progressive hydrocephalus. Arch Dis. Child, 64: 124-8, 1989.

11- BRET P. and CHAZAL J.: Chronic (normal pressure) hydrocephalus in childhood and adolescence. A review of 16 cases and reappraisal of the syndrome. Childs Nerv. Syst., 11: 687-91, 1995.

12- POCA M.A., SAHUQUILLO J., CUXART A., et al.: Intracranial pressure monitoring in patients with spina bifida and clinically arrested hydrocephalus. Results of a prospective study. In: Nagai H., et al., eds. Intracranial pressure IX. Tokyo: Springer-Verlag, 604-5, 1994.

13-ZIELINSKA D., ZEMBATY A. and STAROWICZ-FILIP A.: Cognitive disorders in children's hydrocephalus; Review article. Polish J. Neurology and Neurosurgery, 51: 234-9, 2017.

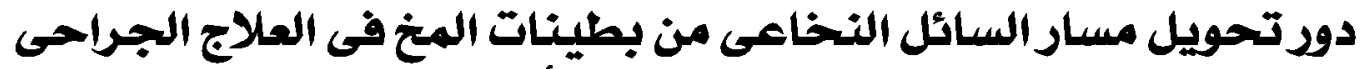

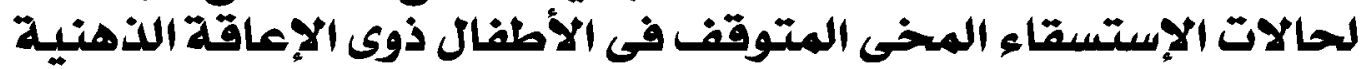

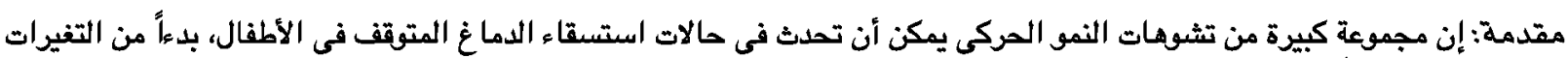

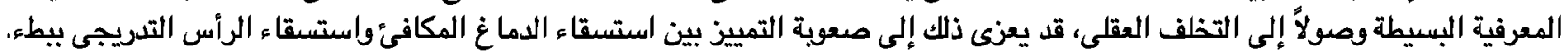

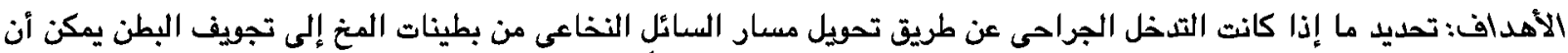

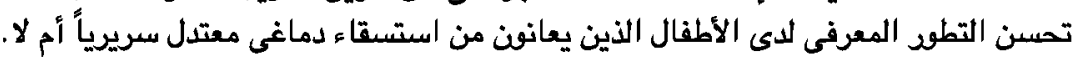

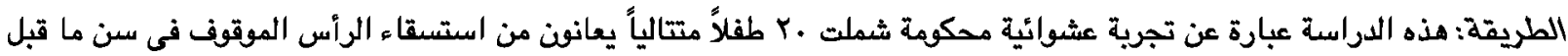

$$
\begin{aligned}
& \text { المدرسة دون أى سبب آخر للتخلف العقلى. جميع المرضى لايهم انحراف فى معدل الذكاء (حاصل الذكاء أقل من المتوسط) وتم تقسيمهم }
\end{aligned}
$$

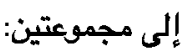

$$
\begin{aligned}
& \text { • المجموعة الأولى: المجموعة الضابطة: تمت متابعة ـأمرضى سريرياً دون أى تدخل علاجى. }
\end{aligned}
$$

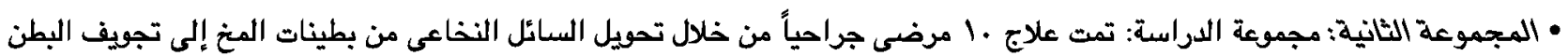

$$
\begin{aligned}
& \text { وتم تقييم اليافوخ الأمامى ومحيط مدار الرأس الأمامى ومعامل الذكاء فى البداية وبعد } 7 \text { أشهر ومقارنة تلك العوامل فى كلا المجينات المجوعتين. } \\
& \text { النتائج: أن تحويل مسار السائل النخاعى من بطينات المخ إلى تجويف البطن أظهر تحسناً فى ه حالات من أصل } 7 \text { وأصبح فحص قاع }
\end{aligned}
$$

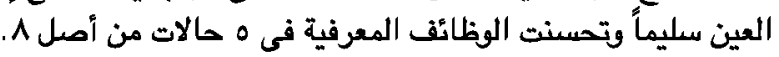

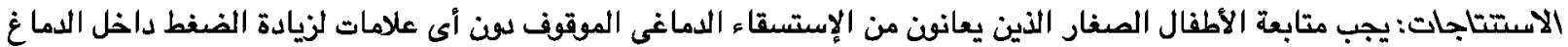

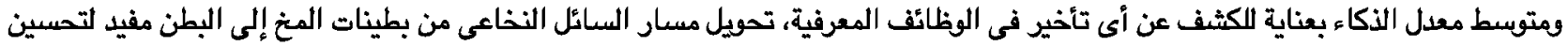

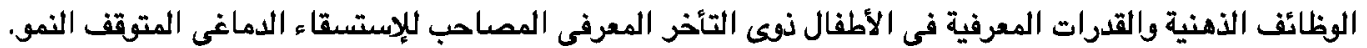

